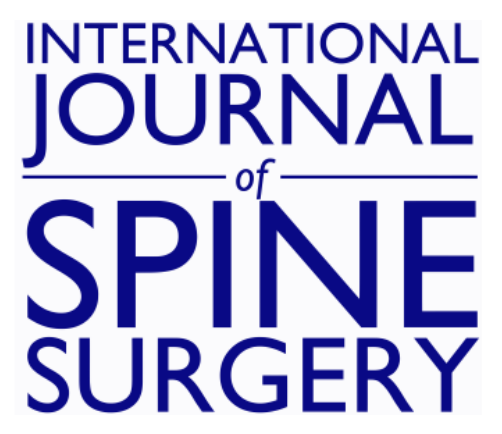

\title{
Comparative Radiographic Analyses and Clinical Outcomes Between O-Arm Navigated and Fluoroscopic-Guided Minimally Invasive Transforaminal Lumbar Interbody Fusion
}

Weerasak Singhatanadgige, Phattareeya Pholprajug, Kittisak Songthong, Wicharn

Yingsakmongkol, Chanonta Triganjananun, Vit Kotheeranurak and Worawat Limthongkul

Int J Spine Surg published online 17 February 2022

http://ijssurgery.com/content/early/2022/03/01/8183

This information is current as of April 26, 2023.

Email Alerts Receive free email-alerts when new articles cite this article. Sign up at: http://ijssurgery.com/alerts 


\title{
Comparative Radiographic Analyses and Clinical Outcomes Between O-Arm Navigated and Fluoroscopic-Guided Minimally Invasive Transforaminal Lumbar Interbody Fusion
}

\author{
WEERASAK SINGHATANADGIGE, MD ${ }^{1,2}$; PHATTAREEYA PHOLPRAJUG, MD ${ }^{1}$; KITTISAK SONGTHONG, MD $^{1}$; \\ WICHARN YINGSAKMONGKOL, MD ${ }^{1,2}$; CHANONTA TRIGANJANANUN, MD ${ }^{1}$; VIT KOTHEERANURAK ${ }^{3}$; AND \\ WORAWAT LIMTHONGKUL, MD ${ }^{1,2}$ \\ ${ }^{I}$ Department of Orthopaedics, Faculty of Medicine, Chulalongkorn University and King Chulalongkorn Memorial Hospital, Bangkok, Thailand; ${ }^{2}$ Center of Excellence \\ in Biomechanics and Innovative Spine Surgery, Chulalongkorn University, Bangkok, Thailand; ${ }^{3}$ Department of Orthopedics, Queen Savang Vadhana Memorial \\ Hospital, Sriracha, Chonburi, Thailand
}

Background: The differences in clinical and radiographic outcomes between 3-dimensional computer navigation (NAV) and fluoroscopic-guided (FLUO) minimally invasive transforaminal lumbar interbody fusion (MIS-TLIF) are currently unclear, with different studies showing different advantages of each technique. This study aimed to compare the clinical and radiographic outcomes of NAV and FLUO MIS-TLIF. Furthermore, we determined the correlation between radiographic findings and predictable clinical outcomes.

Methods: Between January 2016 and October 2018, 97 consecutive patients who had undergone MIS-TLIF with the lumbosacral degenerative disease in our institute were retrospectively reviewed. Radiographic outcomes (angle of screw convergence, screw-to-pedicle diameter ratio, \%screw depth, screw penetration, \%fusion, and facet joint violation) were analyzed by 2 independent orthopedists using thin-slice computed tomography. Clinical outcomes were assessed with Oswestry Disability Index (ODI), visual analog scale (VAS), and satisfaction score. The association between radiographic and clinical outcomes was then analyzed to determine the predictable variable outcomes.

Results: Sixty-one patients (270 screws) in the FLUO group and 36 patients (172 screws) in the NAV group were compared. The NAV group showed a significantly higher \%screw depth $(89.04 \% \pm 6.07 \%$ vs $85.18 \% \pm 7.54 \% ; P=0.011)$, larger angle of screw convergence $\left(27.7^{\circ} \pm 3.93^{\circ}\right.$ vs $\left.18.44^{\circ} \pm 7.54^{\circ} ; P<0.001\right)$, lower incidence of pedicle penetration $(0 \%$ vs $3.7 \% ; P=0.016)$, and less facet joint violation $(1.0 \%$ vs $8.1 \% ; P=0.003)$. The clinical results revealed a significantly better VAS and ODI in the NAV group at 6 and 12 months. The \%screw depth correlated with the VAS back pain score at the 1-year follow-up.

Conclusions: NAV MIS-TLIF showed superior screw placement accuracy, better screw convergence and depth, and lower cranial facet joint violation than FLUO MIS-TLIF. Furthermore, better clinical scores were revealed in the NAV group at the 6-month and 1-year follow-up.

Level of Evidence: 3.

Minimally Invasive Surgery

Keywords: MIS-TLIF, computer-3D navigation, screw accuracy, clinical outcome, radiographic analysis, lumbosacral degenerative disease, facet joint violation, screw convergence, screw depth

\section{INTRODUCTION}

Minimally invasive transforaminal lumbar interbody fusion (MIS-TLIF) can decrease the rate of morbidities related to open surgery, improve clinical outcomes, and reduce back muscle injury. ${ }^{1,2}$ However, the drawbacks of fluoroscopic-guided (FLUO) instrumentation include Kirschner wire complications, incorrect positioning of screws, which can cause spinal nerve root injury, and concerns about radiation exposure. $^{2-6}$ Optimal screw selection is dependent on other surrogate measures, such as lateral radiographs, preoperative computed tomography $(\mathrm{CT})$, and magnetic resonance imaging to ensure precision and safety. ${ }^{7}$ Percutaneous pedicle screw insertion requires reliance on 2-dimensional image guidance; therefore, a higher rate of screw misplacement due to a lack of visibility of anatomical landmarks can occur. ${ }^{4,5,8}$ As it provides the surgeon with a 3-dimensional (3D) intraoperative visual approximation of the anatomy, 3D computer navigation (NAV) can theoretically reduce the surgeon's radiation exposure, improve screw placement accuracy, potentiate the ability to maximize the screw diameter relative to the pedicle, and reduce potential injury to critical 
neurovascular structures. ${ }^{4-6,9,10}$ Combined, these advantages could lead to better clinical outcomes. However, the differences in the clinical outcomes between FLUO and NAV MIS-TLIF are currently unclear. ${ }^{2,9,11}$

The purpose of the present study is to compare the radiographic and clinical outcomes between the newer NAV and conventional FLUO MIS-TLIF procedures. Furthermore, we wanted to establish a correlation between each technique and radiographic and clinical outcomes.

\section{MATERIALS AND METHODS}

\section{Patients and Design}

We performed a single-center retrospective review of patients who had undergone 1- or 2-level MIS-TLIF from January 2016 to December 2018 with either fluoroscopic guidance (FLUO group) or O-arm navigation (NAV group). This study was approved by the human committee of the Faculty of Medicine, Chulalongkorn University Institutional Review Board; the approval number is 583/62. The written informed consent was waived. Patients who had incomplete clinical data or no postoperative CT at 12 months were excluded. Thirty-six patients who met the inclusion criteria in the NAV group were enrolled. For the 150 initial patients in the FLUO group, we performed propensity matching to the NAV group based on age, sex, body mass index, preoperative diagnosis, and operative level, which resulted in 61 eligible patients as historical controls. All surgeries were performed by a single experienced surgeon. Assuming a minimum clinical difference in pain scores of $2 \mathrm{~cm}$ measured by visual analog scale (VAS) with a common SD of 1 , our study would have $>95 \%$ power to detect this difference at any follow-up visits at $90 \%$ power and a 2-sided significance level of $5 \% .^{12}$

\section{Surgical Technique}

\section{MIS-TLIF Using Fluoroscopy}

Patients were placed in the prone position on a radiolucent table. The lumbar area of interest was identified. A parasagittal incision was opened under a FLUO image. Under an anteroposterior fluoroscopic view, the Jamshidi needle was docked at the lateral border of the pedicle and advanced into the pedicle. Under lateral fluoroscopic view, Kirschner wires were replaced through the Jamshidi needles into the vertebral body. The same procedure was repeated at the contralateral site and lower vertebrae. Sequential dilation was performed through the paraspinal muscles. A table-mounted working tubular retractor (METRx II System Tube or MAST QUADRANT System) was placed and docked under fluoroscopic guidance. Surgery was performed under an operating microscope (Carl Zeiss Inc.). Following a total facetectomy, radical discectomy, and endplate preparation, the cage trial was serially inserted under fluoroscopic guidance until the proper size was attained. An appropriate sized CAPSTONE PEEK Interbody Spacer filled with mixed autogenous bone graft and demineralized bone matrix (DBM) was inserted. Percutaneous pedicle screws (CD Horizon Sextant II) were placed into the pedicle guided by the Kirschner wire. A subfascial rod was passed then radivac drain was placed, and the incision was closed.

\section{MIS-TLIF Using CT-Guided Navigation}

The patient was placed in the prone position on a radiolucent table. The navigation reference frame was embedded in the posterior superior iliac crest. The first spin was performed by the $\mathrm{O}$-arm to create a 3D image, and the images were transferred automatically to the StealthStation System. Surgical instruments were registered for intraoperative navigation. The incision was made with the help of the navigation pointer and then serial dilators and insert tubular retractor on the side of decompression toward the facet joint. An operating microscope was used during laminotomy and discectomy. CAPSTONE PEEK Navigated Trials with the green NavLock tracker were inserted into the disc space until the desired disc space height is established. The appropriate sized Interbody Spacer cage, filled with mixed autogenous bone graft and DBM, was inserted into disc space. Then, the second O-arm spin was obtained for screw placement. Using an "awl-tipped tap," penetrated through the pedicle into the vertebral body, percutaneous pedicle screws were inserted as determined from the visualized 3D image from the second spin. A contoured rod was passed underneath the fascia. A third 3D image was obtained for measuring the desired position.

\section{Outcome Measurement}

Demographic data (sex, age, body mass index, diagnosis, and level of operation), intraoperative parameters (blood loss, operative time, and radiation dose), clinical scores, and radiographic outcomes were described as percentage, mean, and SD. 


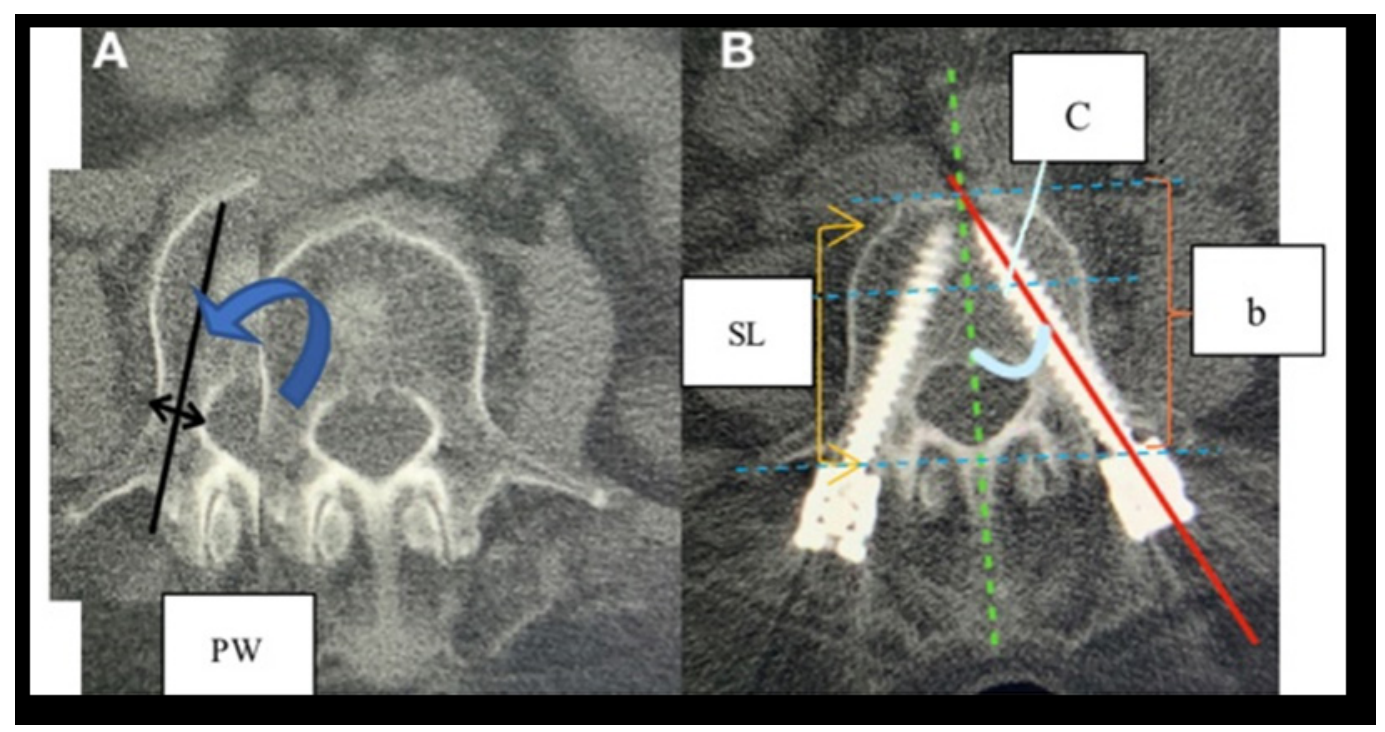

Figure 1. Postoperative thin-slice computed tomography performed at 12 months. $(A) P W=$ pedicle width, $(B) b=$ body length, $S L=s c r e w$ length $(\% S D=[S L / b]$ $\times 100$ ), and $\mathrm{C}=$ angle of medial convergence.

\section{Clinical Evaluation}

The clinical data included the VAS (back and legs), Oswestry Disability Index (ODI), and satisfaction score, which were evaluated at 1 day and 3, 6, and 12 months postoperative. Each was recorded by 1 independent interviewer.

\section{Radiographic Evaluation}

For radiographic evaluation, postoperative thin-slice CT was performed at 12 months. The measurements included:

1. The angle of medial convergence (C), defined as the angle between the screw trajectory line and the vertical axis (Figure 1B)

2. The screw-to-pedicle diameter ratio (SD:PW), defined as the ratio of the screw diameter (SD) to pedicle width (PW) in CT axial slices (Figure 1A)
3. The \%screw depth in relation to the body $(\mathrm{SL} / \mathrm{b})$, defined as the proportion between the screw length (SL) and body length (b) (Figure 1B)

4. Cage subsidence, defined as at least a $2 \mathrm{~mm}$ sink of the cage into the vertebral endplate

5. The severity was then classified using the subsidence grading severity according to Marchi et $\mathrm{al}^{13}$ (Figure 2)

6. The grade of screw perforation, as classified by the severity of screw perforation grading (Gertzbein system), with Grade 0: screw within pedicle (no breach), Grade 1: screw thread breach of pedicle $<2 \mathrm{~mm}$, Grade 2: screw breach 2-4 $\mathrm{mm}$, and Grade 3: screw breach $>4 \mathrm{~mm}$ (Figure 3$)^{3}$

7. Cage size, collected from medical records

8. Bony fusion, defined as solid trabecular bridging between the adjacent endplate, either inside or outside the cage in thin-slice CT

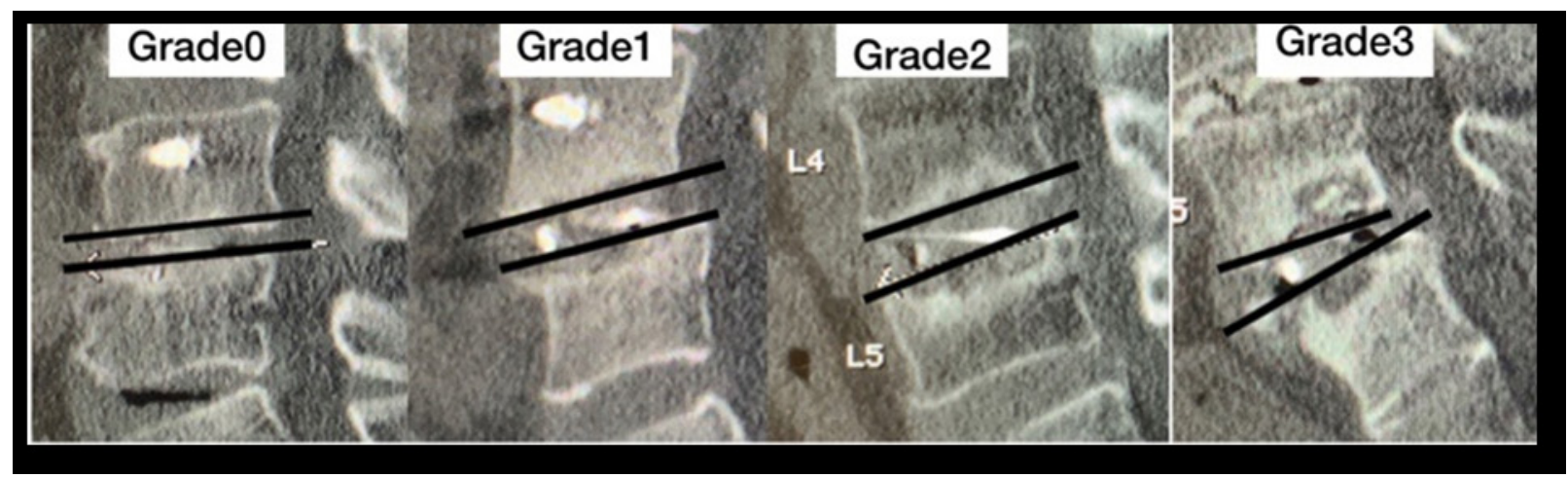

Figure 2. Cage subsidence grading (0-3). 


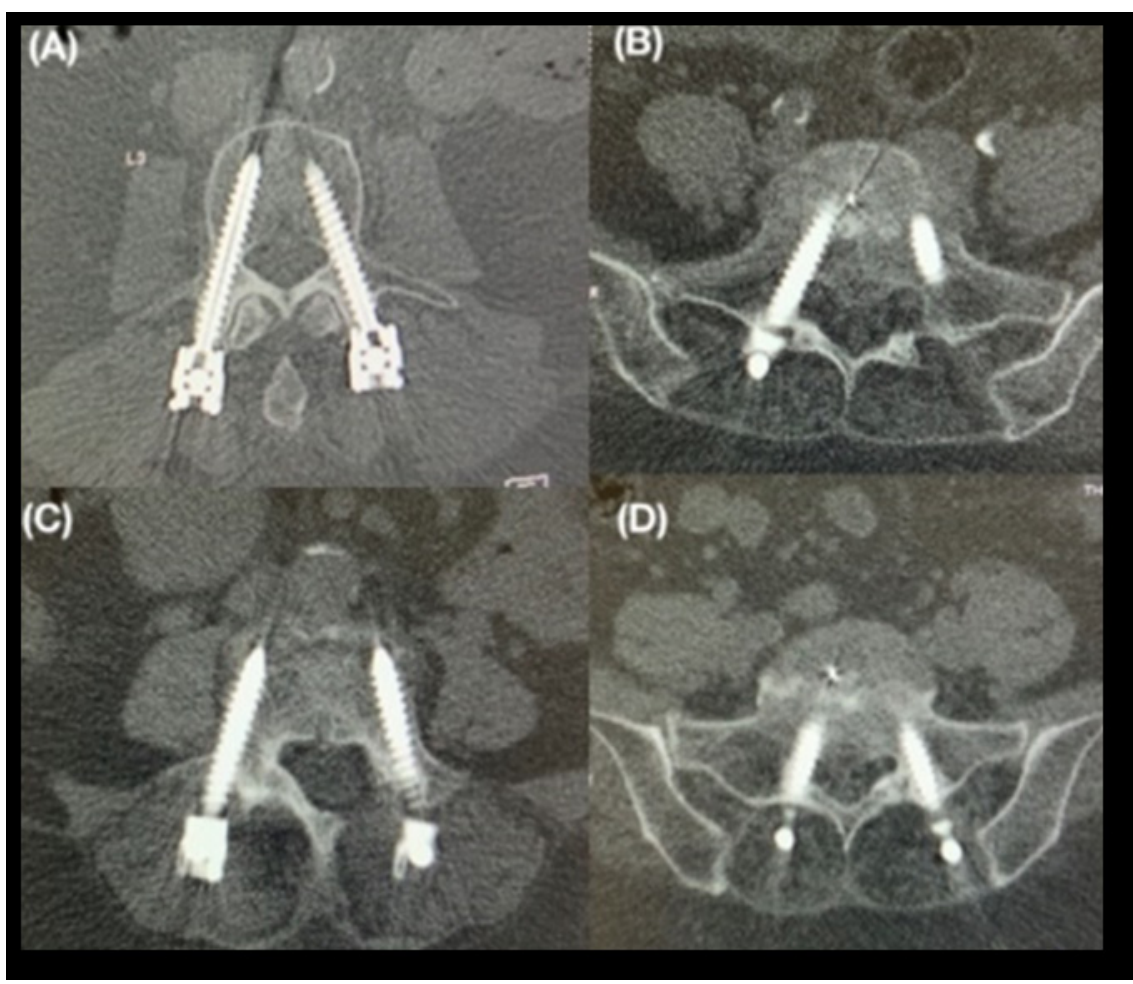

Figure 3. The grading system (Gertzbein). (A) Grade 0: screw within pedicle, (B) Grade 1: screw thread breach of pedicle $\leq 2 \mathrm{~mm}$, (C) Grade 2: significant breach 2-4 mm, and (D) Grade 3: significant breach $>4 \mathrm{~mm}$.

9. Facet joint violation, recorded if there was any cranial facet involvement of the pedicle screw in any axial cut CT scan (Figure 4)

The measurements were performed twice each by 2 orthopedists working independently. Inter- and intraobserver reliability was calculated by interclass correlation coefficients (ICCs).

\section{Statistical Analyses}

All data were analyzed by descriptive statistics, summarized as frequency, percentage, or mean. The difference between both groups in clinical, intraoperative, and radiographic outcomes was analyzed by an independent $t$ test and Fisher's exact test. Pearson's correlation coefficient was used to analyze the association between radiographic and clinical outcome variables.

All $P$ values were 2 -sided with statistical significance set at the $0.05 \alpha$ level. All analyses were performed in SPSS Version 23.0 by an independent statistician.
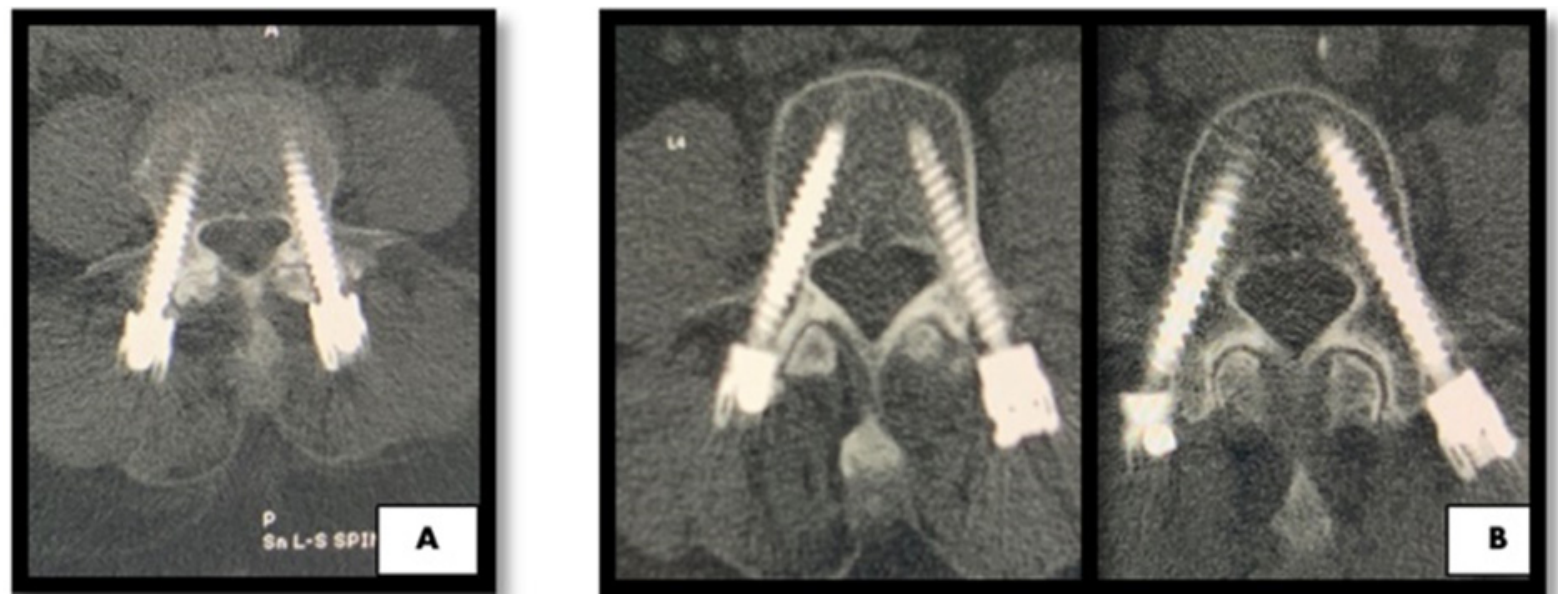

Figure 4. Facet joint violation. (A) Intra-articular pedicle screw that penetrates the facet joint transversely, interposed between the superior and inferior facet at the cephalad level. (B) Screw did not transverse the facet joint; extra-articular screw. 
Table 1. Patient demographic data.

\begin{tabular}{|c|c|c|c|}
\hline Patient Data & FLUO MIS-TLIF $(N=61)$ & NAV MIS-TLIF $(N=36)$ & $P$ Value \\
\hline Age & $65.67 \pm 9.23$ & $65.89 \pm 9.69$ & 0.913 \\
\hline \multicolumn{4}{|l|}{ Sex } \\
\hline Female & $41(67.2 \%)$ & $23(63.9 \%)$ & 0.825 \\
\hline Male & $20(32.8 \%)$ & $13(36.1 \%)$ & 0.825 \\
\hline Body mass index & $25.22 \pm 2.96$ & $24.86 \pm 3.31$ & 0.660 \\
\hline \multicolumn{4}{|l|}{ Diagnosis } \\
\hline Spondylolisthesis & $24(39.3 \%)$ & $22(61.1 \%)$ & 0.058 \\
\hline Spinal stenosis & $7(11.5 \%)$ & $2(5.6 \%)$ & 0.477 \\
\hline Spinal canal stenosis & $17(27.9 \%)$ & $8(22.2 \%)$ & 0.634 \\
\hline Herniated nucleus pulposus & $12(19.7 \%)$ & $3(8.3 \%)$ & 0.159 \\
\hline Degenerative scoliosis & $0(0 \%)$ & $1(2.8 \%)$ & 0.371 \\
\hline Degenerative disc disease & $1(1.6 \%)$ & $0(0 \%)$ & 1.000 \\
\hline \multicolumn{4}{|l|}{ Level } \\
\hline L3-4 & $3(4.9 \%)$ & $2(5.6 \%)$ & 0.745 \\
\hline L3-5 & $7(11.5 \%)$ & $6(16.6 \%)$ & 0.703 \\
\hline L4-5 & $38(62.3 \%)$ & $20(55.6 \%)$ & 0.612 \\
\hline L4-S1 & $6(9.8 \%)$ & $4(11.1 \%)$ & 0.800 \\
\hline L5-S1 & $7(11.5 \%)$ & $4(11.1 \%)$ & 0.258 \\
\hline Blood loss (mL) & $171.03 \pm 157.75$ & $124.44 \pm 147.42$ & 0.157 \\
\hline Operative time ( $\mathrm{min})$ & $173.91 \pm 52.93$ & $163.64 \pm 52.06$ & 0.360 \\
\hline Length of stay (d) & $5.2 \pm 2.41$ & $5.03 \pm 2.46$ & 0.751 \\
\hline Radiation dose (mGy) & $38.26 \pm 5.66$ & $11.49 \pm 2.13$ & $<0.05$ \\
\hline
\end{tabular}

Abbreviations: FLUO, fluoroscopic-guided; MIS-TILF, minimally invasive transforaminal lumbar interbody fusion; NAV, 3-dimensional computer navigation. Data presented as mean $\pm \mathrm{SD}$ or $n(\%)$.

\section{RESULTS}

\section{Patient Characteristics}

The $\mathrm{O}$-arm navigation procedures were done between January 2018 and December 2018 after the technique was available, while the historical controls were all enrolled patients with FLUO MIS-TLIF between January 2017 and December 2017 who met the inclusion criteria.

A total of 97 patients (64 women, 33 men, and 442 screws) with degenerative lumbosacral disease who underwent MIS-TLIF were included in the study. Sixtyone patients (270 screws) underwent surgery using conventional FLUO MIS-TLIF, and 36 patients (172 screws) underwent surgery using NAV MIS-TLIF. The mean age was $65.89 \pm 9.69$ years in the NAV group and $65.67 \pm 9.23$ years in the FLUO group, which was equally matched based on sex, preoperative diagnosis, and operative level. Operative time was not significantly different between the 2 groups $(173.91 \pm 52.93$ minutes in the FLUO group and $163.64 \pm 52.06$ minutes in the NAV group, $P=0.36$; Table 1 ). The mean cumulative radiation exposure in the FLUO group was $38.26 \pm 5.66$ mGy compared to $11.49 \pm 2.13 \mathrm{mGy}$ in the NAV group.

\section{Radiographic Evaluation of Outcomes}

The measurement of radiographic parameters by both orthopedists showed good reliability (intraobserver ICC: 0.869 and interobserver ICC: 0.887). Radiographic outcomes measured via a CT scan at 12 months postoperative are shown in Table 2 . The cage size in the NAV group $(24.78 \pm 1.74)$ showed a significantly larger than the FLUO group $(23.61 \pm 1.93$, $P=0.003)$. There was a significantly higher $\%$ screw depth in the NAV group $(89.04 \% \pm 6.07 \%)$ compared with the FLUO group $(85.18 \% \pm 7.54 \%, P=0.001)$. In addition, the angle of screw convergence in the NAV group was significantly higher compared to the FLUO group $\left(27.7^{\circ} \pm 3.93^{\circ}\right.$ vs $18.44^{\circ} \pm 11.55^{\circ}$ respectively, $P<0.001)$. Regarding accuracy, there was no medial pedicle penetration in the NAV group, whereas 10

Table 2. Comparison of radiographic outcomes between the 2 groups.

\begin{tabular}{lccc}
\hline Raidographic & $\begin{array}{c}\text { FLUO MIS- } \\
\text { PLIF }(\boldsymbol{N}=\mathbf{6 1})\end{array}$ & $\begin{array}{c}\text { NAV MIS-TLIF } \\
(\boldsymbol{N}=\mathbf{3 6})\end{array}$ & $\boldsymbol{P}$ Value \\
\hline Screw-to-pedicle ratio & $0.7 \pm 0.13$ & $0.66 \pm 0.09$ & 0.079 \\
\% Screw depth & $85.18 \pm 7.54$ & $89.04 \pm 6.07$ & $0.011^{\mathrm{a}}$ \\
Angle of medial & $18.44 \pm 11.55$ & $27.7 \pm 3.93$ & $<0.001^{\mathrm{a}}$ \\
$\quad$ convergence & $(n=270)$ & $(n=172)$ & \\
$\%$ Screw penetration & $47(17.4 \%)$ & $16(9.7 \%)$ & $0.027^{\mathrm{a}}$ \\
$\quad$ Anterior & $5(1.9 \%)$ & $4(2.4 \%)$ & 0.684 \\
$\quad$ Lateral & $10(3.7 \%)$ & $0(0 \%)$ & $0.012^{\mathrm{a}}$ \\
$\quad$ Medial & $1(0.4 \%)$ & $1(0.6 \%)$ & 0.724 \\
$\quad$ Superior & $23.61 \pm 1.93$ & $24.78 \pm 1.74$ & $0.003^{\mathrm{a}}$ \\
Cage size & $24(44.4 \%)$ & $30(55.6 \%)$ & 0.471 \\
Cage location & $49(74.2 \%)$ & $17(25.8 \%)$ & 0.471 \\
$\quad$ Anterior & $39(63.9 \%)$ & $23(63.9 \%)$ & 0.996 \\
$\quad$ Posterior & $55(90.2 \%)$ & $33(91.7 \%)$ & 0.481 \\
Cage subsidence $(>2$ & mm) & &
\end{tabular}

Abbreviations: FLOU, fluoroscopic-guided; MIS-TILF, minimally invasive transforaminal lumbar interbody fusion; NAV, 3-dimensional computer navigation. Data presented as mean $\pm \mathrm{SD}$ or $n(\%)$.

${ }^{\text {a }}$ Statistically significant $(P<0.05)$ 
screws $(2.3 \%)$ had medial penetration in the FLUO group $(P=0.016)$. One screw in the FLUO group showed Grade 3 medial pedicle penetration, which required reoperation. Anterior cortex penetration was observed with 47 screws (17.4\%) in the FLUO group (Grades 1 and 2), which was significantly higher than in the NAV group (16 screws, $9.3 \% ; P=0.035$ ). Nevertheless, anterior cortex penetration was found at the S1 level in a majority in both NAV and FLUO groups, which may have been caused by aiming to perform bicortical fixation. However, the mean penetration distance from the anterior cortex of S1 to the tip of the screw was also revealed to be longer in the FLUO group $(6.26 \pm 1.82 \mathrm{~mm})$ compared with the NAV group (1.38 $\pm 4.34 \mathrm{~mm}, P<0.001)$. The maximum anterior penetration from the $\mathrm{S} 1$ anterior cortex was $12.27 \mathrm{~mm}$ in the FLUO group, compared to $5.48 \mathrm{~mm}$ in the NAV group. Furthermore, facet joint violation in the NAV group was observed with only 1 screw $(0.2 \%)$, compared to 22 screws in the FLUO group (5\%; $P=0.003)$. There were no statistically significant differences between groups in the fusion and subsidence rate at 12 months postoperative (Table 2).

\section{Clinical Evaluation of Outcomes}

In the clinical aspect (Table 3), the preoperative back and leg VAS and ODI scores were not significantly different between the 2 groups. The mean VAS (back) in the

Table 3. Comparison of clinical results over time between the 2 groups.

\begin{tabular}{|c|c|c|c|}
\hline \multirow[b]{2}{*}{ Clinical Scores } & FLUO MIS-TLIF & NAV MIS-TLIF & \multirow[b]{2}{*}{$P$ Value } \\
\hline & Mean \pm SE & Mean \pm SE & \\
\hline \multicolumn{4}{|c|}{ VAS of back score } \\
\hline Pre-OP & $6.48 \pm 0.43$ & $7.14 \pm 0.45$ & 0.312 \\
\hline $1 \mathrm{mo}$ & $1.13 \pm 0.23$ & $0.78 \pm 0.26$ & 0.325 \\
\hline $3 \mathrm{mo}$ & $0.72 \pm 0.2$ & $0.48 \pm 0.22$ & 0.454 \\
\hline $6 \mathrm{mo}$ & $0.83 \pm 0.25$ & $0.43 \pm 0.23$ & 0.361 \\
\hline $1 \mathrm{y}$ & $0.63 \pm 0.2$ & $0.11 \pm 0.11$ & $0.025^{\mathrm{a}}$ \\
\hline \multicolumn{4}{|l|}{ VAS leg score } \\
\hline Pre-OP & $6.9 \pm 0.38$ & $7.56 \pm 0.39$ & 0.261 \\
\hline $1 \mathrm{mo}$ & $1.32 \pm 0.27$ & $1.14 \pm 0.23$ & 0.649 \\
\hline $3 \mathrm{mo}$ & $1.11 \pm 0.29$ & $0.58 \pm 0.21$ & 0.143 \\
\hline $6 \mathrm{mo}$ & $1.07 \pm 0.29$ & $0.13 \pm 0.12$ & $<0.001^{\mathrm{a}}$ \\
\hline $1 \mathrm{y}$ & $0.78 \pm 0.26$ & $0.11 \pm 0.11$ & $0.019^{\mathrm{a}}$ \\
\hline \multicolumn{4}{|l|}{ ODI } \\
\hline Pre-OP & $49.07 \pm 2.06$ & $53.83 \pm 1.91$ & 0.123 \\
\hline $1 \mathrm{mo}$ & $11.86 \pm 1.74$ & $11.69 \pm 1.89$ & 0.949 \\
\hline $3 \mathrm{mo}$ & $8.26 \pm 2$ & $4.39 \pm 1.73$ & 0.200 \\
\hline $6 \mathrm{mo}$ & $6.86 \pm 1.86$ & $0.67 \pm 0.67$ & $0.003^{\mathrm{a}}$ \\
\hline $1 \mathrm{y}$ & $5.21 \pm 1.69$ & $0.49 \pm 0.49$ & $0.009^{\mathrm{a}}$ \\
\hline \multicolumn{4}{|l|}{ Satisfaction score } \\
\hline $1 \mathrm{mo}$ & $8.81 \pm 0.23$ & $9.31 \pm 0.14$ & 0.068 \\
\hline $3 \mathrm{mo}$ & $8.82 \pm 0.23$ & $9.42 \pm 0.16$ & 0.081 \\
\hline $6 \mathrm{mo}$ & $8.93 \pm 0.23$ & $9.35 \pm 0.15$ & 0.302 \\
\hline $1 \mathrm{y}$ & $9.16 \pm 0.18$ & $9.39 \pm 0.16$ & 0.495 \\
\hline
\end{tabular}

Abbreviations: FLUO, fluoroscopic-guided; MIS-TILF, minimally invasive transforaminal lumbar interbody fusion; NAV, 3-dimensional computer navigation. ${ }^{\mathrm{a}}$ Statistically significant $(P<0.05)$.
NAV group was significantly lower than in the FLUO group at 12 months postoperative $(P=0.004)$. Furthermore, the mean VAS (legs) was also significantly lower in the NAV group compared to that of the FLUO group at 6 months $(P<0.001)$ and 12 months postoperative $(P=0.019)$. The mean ODI improvement in the NAV group was significantly better than in the FLUO group at 6 and 12 months postoperative $(P=0.003$ and 0.009 , respectively). However, the satisfaction score was not significantly different between the 2 groups at any timepoint within the 12 months of follow-up.

\section{Correlation Between Radiographic Parameters and Clinical Outcomes}

The correlation analysis of the radiographic parameters and clinical outcomes is shown a significant difference in \%screw depth among the 2 groups was the only parameter to show a correlation with the VAS (back) score at the 12-month postoperative follow-up $(P=$ $0.022, r=-0.26)$.

\section{DISCUSSION}

NAV MIS-TLIF showed superior screw placement accuracy, better screw convergence and depth, larger cage size, and lower cranial facet joint violation compared to FLUO MIS-TLIF. Furthermore, better clinical scores were revealed in the NAV group at the 6- and 12-month follow-ups. Correlation analysis revealed that the difference in \%screw depth between the 2 groups correlated with the VAS (back) score at the 12-month postoperative follow-up. The navigation availability was started in January 2018 so that the fluoroscopic arm constitutes a historical "control." This may simply constitute an improvement of the surgeon in their techniques. We, therefore, included the patients in fluoroscopic groups after 100 cases of experience of the surgeon to reduce this bias.

In recent years, advanced imaging has become widely used in minimally invasive procedures. The superiority of navigation-based systems is clear regarding the accuracy, especially in abnormal spine anatomy with degenerative changes. ${ }^{4,5}$. Furthermore, Dusad et al showed that NAV significantly reduced the surgeon's radiation exposure by up to 9.96 times. ${ }^{5}$ This is concordant with our study results, which revealed a reduction in radiation exposure of the patients by at least 3-fold compared to FLUO, whereas the surgeon and surgical team would receive far less radiation exposure because they can leave the operating room while spinning the $\mathrm{O}$-arm. 
Mathew et $\mathrm{al}^{14}$ found that $\mathrm{O}$-arm NAV pedicle screw insertion was associated with a low incidence of pedicle breach (1\%). This was similar to the results of our study, which revealed an absence of medial pedicle breach in the NAV group, but a breach rate of $3.7 \%$ in the FLUO group $(P=0.016)$. Therefore, the $\mathrm{O}$-arm navigated system can guide the safe insertion of a large screw without critical pedicle penetration. Similarly, Torres et $\mathrm{al}^{9}$ demonstrated that the NAV system afforded safe and accurate screw placement with larger diameter screws ( $\geq 7 \mathrm{~mm})$.

For anterior perforation mainly at the $\mathrm{S} 1$ screw, the mean perforating distances were longer in the FLUO group compared to the NAV group. When referring to a previous study, the closest major vascular structure to the $\mathrm{S} 1$ anterior cortex was $13-15 \mathrm{~mm} .{ }^{15,16}$ The increased safety in the NAV group is supported by the maximum penetration being only $5.48 \mathrm{~mm}$ from the $\mathrm{S} 1$ anterior cortex. In contrast, the FLUO group showed a $12.27 \mathrm{~mm}$ distance as the maximum penetration. This issue should be kept in mind when performing bicortical fixation using the FLUO technique.

In a previous biomechanics study, Barber et al indicated that a good pull-out strength of the pedicle screw was significantly related to greater than $30^{\circ}$ of screw convergence. ${ }^{17}$ In addition, Karami et al found that increasing screw depth led to more stiffness and reduced loosening. ${ }^{18}$ In our study, the NAV group showed superiority in increased screw convergence and higher \%screw depth, which allowed the surgeon to create the best construct stability without risking breach. ${ }^{10,17,18}$ Concordantly with clinical outcomes, deeper screw insertion was correlated with a more favorable VAS (back) at the 12-month follow-up, which might be due to more stable fixation. The larger cage size might affect the improvement in VAS (leg) at 6- and 12-month follow-up due to the indirect decompression effect.

Regarding facet joint violation, Teles et al discovered an increased facet joint violation in percutaneous minimally invasive techniques in comparison to the open technique. ${ }^{19}$ Furthermore, Ohba et al indicated that facet joint violation was significantly lower in NAV compared with FLUO, which may result in a decrease in adjacent segment degeneration. ${ }^{20}$ Similarly, in our findings, facet joint violation was higher in the FLUO group than in the NAV group. Despite the similarities in percutaneous technique, NAV screw fixation avoided facet joint violation due to clear visibility with a $3 \mathrm{D}$ image during screw insertion. The lower rate of cranial facet violation could theoretically reduce the incidence of adjacent segment degeneration. ${ }^{19}$
Adequate decompression is the most important factor for early postoperative clinical outcomes. The same surgical decompression technique in the 2 study groups (microscopic-assisted decompression) meant there was no difference in the immediate postoperative clinical results, as well as at the 1- and 3-month follow-ups. However, clinical results revealed a better VAS and ODI in the NAV group at the 6- and 12-month follow-ups. This may have resulted from the more stable construction (more convergence and increased \%screw depth) using NAV pedicle screw placement.

There were some limitations to our study, including its retrospective design, lack of randomization in patient enrollment, and a sample size that was too small to detect secondary outcomes. Further prospective, long-term studies are required for a better understanding of the improvements in clinical outcomes afforded by navigated MIS-TLIF.

\section{CONCLUSIONS}

The NAV MIS-TLIF showed superior screw placement accuracy, increased screw convergence and depth, and reduced cranial facet joint violation compared to FLUO MIS-TLIF. Furthermore, although not meeting the clinically significant criteria, more favorable clinical scores (VAS back, VAS leg, and ODI) were revealed in the NAV group at the 6- and 12-month follow-ups.

\section{ACKNOWLEDGMENTS}

We would like to thank Prof. Steve Kerr for his invaluable suggestions on the statistical analyses in this manuscript.

\section{REFERENCES}

1. Fan S, Hu Z, Zhao F, Zhao X, Huang Y, Fang X. Multifidus muscle changes and clinical effects of one-level posterior lumbar interbody fusion: minimally invasive procedure versus conventional open approach. Eur Spine J. 2010;19(2):316-324. doi:10.1007/ s00586-009-1191-6

2. Chen K, Chen H, Zhang K, et al. O-arm navigation combined with microscope-assisted MIS-TLIF in the treatment of lumbar degenerative disease. Clin Spine Surg. 2019;32(5):E235-E240. doi:10.1097/BSD.0000000000000804

3. Sadrameli SS, Jafrani R, Staub BN, Radaideh M, Holman PJ. Minimally invasive, stereotactic, wireless, percutaneous pedicle screw placement in the lumbar spine: accuracy rates with 182 consecutive screws. Int J Spine Surg. 2018;12(6):650-658. doi:10.14444/5081

4. Luther N, Iorgulescu JB, Geannette C, et al. Comparison of navigated versus non-navigated pedicle screw placement in 260 patients and 1434 screws: screw accuracy, screw size, and the 
complexity of surgery. J Spinal Disord Tech. 2015;28(5):E298-303. doi:10.1097/BSD.0b013e31828af33e

5. Dusad T, Kundnani V, Dutta S, Patel A, Mehta G, Singh M. Comparative prospective study reporting intraoperative parameters, pedicle screw perforation, and radiation exposure in navigationguided versus non-navigated fluoroscopy-assisted minimal invasive transforaminal lumbar interbody fusion. Asian Spine J. 2018;12(2):309-316. doi:10.4184/asj.2018.12.2.309

6. Pennington Z, Cottrill E, Westbroek EM, et al. Evaluation of surgeon and patient radiation exposure by imaging technology in patients undergoing thoracolumbar fusion: systematic review of the literature. Spine J. 2019;19(8):1397-1411. doi:10.1016/j. spinee.2019.04.003

7. Luther N, Iorgulescu JB, Geannette C, et al. Comparison of navigated versus non-navigated pedicle screw placement in 260 patients and 1434 screws: screw accuracy, screw size, and the complexity of surgery. J Spinal Disord Tech. 2015;28(5):E298-303. doi:10.1097/BSD.0b013e31828af33e

8. Chua MJ, Siddiqui S, CS Y, Nolan CP, J-L O. The optimal screw length of lumbar pedicle screws during minimally invasive surgery fixation: a computed tomography-guided evaluation of 771 screws. Asian Spine J. 2019;13(6):936-941. doi:10.31616/ asj.2018.0276

9. Torres J, James AR, Alimi M, Tsiouris AJ, Geannette C, Härtl R. Screw placement accuracy for minimally invasive transforaminal lumbar interbody fusion surgery: a study on 3-d neuronavigation-guided surgery. Global Spine J. 2012;2(3):143-152. doi:10.1055/s-0032-1326949

10. Jendoubi K, Khadri Y, Bendjaballah M, Slimane N. Effects of the insertion type and depth on the pedicle screw pullout strength: a finite element study. Appl Bionics Biomech. 2018;2018:1460195. doi:10.1155/2018/1460195

11. Khanna R, McDevitt JL, Abecassis ZA, et al. An outcome and cost analysis comparing single-level minimally invasive transforaminal lumbar interbody fusion using intraoperative fluoroscopy versus computed tomography-guided navigation. World Neurosurg. 2016;94:255-260. doi:10.1016/j.wneu.2016.07.014

12. Glassman SD, Copay AG, Berven SH, Polly DW, Subach BR, Carreon LY. Defining substantial clinical benefit following lumbar spine arthrodesis. J Bone Joint Surg Am. 2008;90(9):1839-1847. doi:10.2106/JBJS.G.01095

13. Marchi L, Abdala N, Oliveira L, Amaral R, Coutinho E, Pimenta L. Radiographic and clinical evaluation of cage subsidence after stand-alone lateral interbody fusion. J Neurosurg Spine. 2013;19(1):110-118. doi:10.3171/2013.4.SPINE12319

14. Mathew JE, Mok K, Goulet B. Pedicle violation and navigational errors in pedicle screw insertion using the intraoperative O-arm: a preliminary report. Int J Spine Surg. 2013;7:e88-94. doi:10.1016/j.ijsp.2013.06.002
15. Akhgar J, Terai H, Suhrab Rahmani M, et al. Anatomical location of the common iliac veins at the level of the sacrum: relationship between perforation risk and the trajectory angle of the screw. Biomed Res Int. 2016;2016:1457219. doi:10.1155/2016/1457219

16. Ergur I, Akcali O, Kiray A, Kosay C, Tayefi H. Neurovascular risks of sacral screws with bicortical purchase: an anatomical study. Eur Spine J. 2007;16(9):1519-1523. doi:10.1007/s00586007-0326-X

17. Barber JW, Boden SD, Ganey T, Hutton WC. Biomechanical study of lumbar pedicle screws: does convergence affect axial pullout strength? J Spinal Disord. 1998;11(3):215-220.

18. Karami KJ, Buckenmeyer LE, Kiapour AM, et al. Biomechanical evaluation of the pedicle screw insertion depth effect on screw stability under cyclic loading and subsequent pullout. J Spinal Disord Tech. 2015;28(3):E133-9. doi:10.1097/ BSD.0000000000000178

19. Teles AR, Paci M, Gutman G, et al. Anatomical and technical factors associated with superior facet joint violation in lumbar fusion. J Neurosurg Spine. 2018;28(2):173-180. doi:10.3171/2017. 6.SPINE17130

20. Ohba T, Ebata S, Fujita K, Sato H, Haro H. Percutaneous pedicle screw placements: accuracy and rates of cranial facet joint violation using conventional fluoroscopy compared with intraoperative three-dimensional computed tomography computer navigation. Eur Spine J. 2016;25(6):1775-1780. doi:10.1007/s00586-0164489-1

Funding: The author(s) received no financial support for the research, authorship, and/or publication of this article.

\section{Declaration of Conflicting Interests:} Weerasak Singhatanadgige and Worawat Limthongkul are consultants of Medtronic (Thailand) Limited. The remaining authors have no disclosures.

Corresponding Author: Worawat Limthongkul, Chulalongkorn University and King Chulalongkorn Memorial Hospital, 1873 Rama IV road, Pathumwan, Bangkok 10330, ThailandPhone: +662 256 4230Fax: +6622 2564510 E-mail: ; dr.worawat@gmail.com

Published 15 February 2022

This manuscript is generously published free of charge by ISASS, the International Society for the Advancement of Spine Surgery. Copyright () 2022 ISASS. To see more or order reprints or permissions, see http:// ijssurgery.com. 